\title{
THE PRACTICES OF THE EVENTFUL CITY: THE CASE OF INCUBATE FESTIVAL
}

\author{
ILJA SIMONS \\ Academy for Leisure, NHTV, Breda, The Netherlands
}

\begin{abstract}
The use of events as policy tools in cities has become widely recognized. However, most studies concerning this topic do not capture the complex interrelationships that underpin the development of an eventful city. This study applies a practice approach, in order to analyze the dynamics of the eventful city practice. It places the urban event practice centrally in the analysis and focuses on the actual "sayings and doings" of the practice. The event practice of the 2015 Incubate festival in Tilburg, the Netherlands, is analyzed by means of ethnographic methods, including participant observation and interviews. Incubate illustrates how both the city and the event are performed within the practice: the event shapes the city and the city shapes the event. However, the integration of the festival into alternative spaces in the city means that it does not increase the visibility of Tilburg, and therefore fails to deliver value to its eventful city policy.
\end{abstract}

Key words: Eventful cities; Practice approach; Festival; Events; Qualitative research

\section{Introduction}

In their book Eventful Cities Richards and Palmer (2010) described the increasing use of events as policy tools in cities. The use of events as strategic placemaking tools is becoming more widely recognized (De Brito \& Richards, 2017). Events are said to make cities more meaningful by emphasizing specific times (Smith, 2016) and they are able to generate a wide range of economic and social benefits (De Brito \& Richards, 2017). This has led to a variety of strategies and practices emerging in cities to develop or attract events. For example, cities try to create eventfulness by developing event portfolios (Antchak, 2016; Ziakas, 2014) or bidding for events. However, the rationale for event development is often economic and based on commercial events (Smith, 2016).

The relationship between cities and events is complex and consists of many interrelated practices. Smith (2016) describes this in terms of "the urbanization of events"; or events being increasingly staged in urban public spaces, and through "the eventalization of urban space”; where urban space is produced by the staging of events. This emphasizes the recursive nature of the relationship between 
cities and events, in which events produce spaces that in turn require animation through the development of events, driving the growth of eventfulness and the adoption of eventful city policies.

Most previous studies have approached these issues from a one-dimensional (often economic) perspective, which fails to capture the wide range of interrelationships that underpin the development of an eventful city. Existing studies focus on either an event management perspective, which sometimes incorporates the city as a stage for events, but does not focus on the relationships between events and cities. On the other hand, we can detect a more structure-centered approach, which emphasizes governance practices such as event policies and the development of event portfolios. Although these studies provide useful insights into the staging of events in cities, they tend to portray a dichotomy between the event and the city. But, although policy makers and event organizers might see themselves as involved in separate practices, in an eventful city meaning and value are created through practices in which the city and the event interact.

A practice approach offers a more holistic perspective on events and eventful cities that can help us to analyze these interactions. In a practice approach, the focus of the analysis is on the actual "doings and sayings" (Spaargaren, Lamers, \& Weenink, 2016) of the urban event practice. Applying a practice approach to the concept of the eventful city has two advantages. Firstly, a practice approach provides structure to the contextual conditions that are created by the city, which makes it possible to reflect on how these different conditions create synergy or contradict each other. Secondly, through focusing on the actual urban event practice, it becomes clear that the city is not only the context in which the event is organized, but it is a vital part of the meaning that is created within the practice. This leads to another notion of events and the city: instead of using each other for benefits, they are entangled into one "eventful city practice."

This article zooms in on one urban event practice, by means of a case study approach. Through ethnographic methods such as participant observation and interviews, the practice of Incubate festival, as well as the relationship between this event and the Dutch city of Tilburg were studied. Incubate festival is an independent cultural festival that has been organized in the city of Tilburg since 2005 . The case study illustrates the multidimensionality of the city as a context for the event as well as the way both the city and the event are performed during the practice, leading to a perceived inseparability of city and event, and thereby challenging the event versus city dichotomy.

\section{Literature Review}

\section{Events as Practices}

In order to study the dynamics of the eventful city, this study adopts a practice approach (Bargeman, 2001; Reckwitz, 2002; Shove, Pantzar, \& Watson, 2012; Spaargaren et al., 2016; van der Poel, 2004). Practices are produced by actors, but conditioned by systems and structures. This results in a dualistic model, which places the practices at the heart of the analysis (Shove et al., 2012; Warde, 2014). Individuals become the "carriers" (Reckwitz, 2002) of practices, carrying out the various activities and tasks that the practice requires. Practices recruit practitioners through their meanings (Shove et al., 2012). This makes it possible to study the meaning of practices via the participants of the practice.

There are many different approaches to the study of practices. For example, Hargreaves (2011) made a distinction between scholars who focus on the various elements that make up a practice, scholars who emphasize the connections between these elements, and a third group that focuses on the position of practices as a bridge between individuals and systems of provision. What all scholars of practices agree on is that in applying a practice approach, the practice itself becomes central to the analysis.

Applying a practice approach to the concept of the eventful city leads to a fundamentally different perspective, because the focus of the analysis is shifted away from the decision makers within eventful cities to the actual "doing" of the practice (Hargreaves, 2011; Spaargaren et al., 2016). By focusing on the practice, the question of "who is serving whom?” in the eventful city is reframed into to "how is the eventful city performed by actors, together?"

In examining the performance of the practice, it is also important to understand how the practice is conditioned by other systems and structures. This 
article considers how these contexts relate to the way the practice is performed and perceived. van der Poel (2004) distinguished three types of contextual conditions: time-space, material, and structural conditions (Bargeman, 2001; van der Poel, 2004), which enable or constrain the practice.

\section{Time-Space Conditioning}

The first type of contextual conditions of a leisure practice, as distinguished by van der Poel (2004), is time-space conditioning. Time-space conditioning refers to distances in time and space or the situating of actors in social and physical systems. Events are per definition limited in time and space (de Geus, Richards, \& Toepoel, 2016; Getz, 1989; Jago \& Shaw, 1998; Morgan, 2008). In the context of eventful cities, this raises the question: to what extent and in what way does the city benefit from the time the event is staged in a particular space in the city?

Cities expect to benefit from events through their contribution to the development of sense of place, by building local pride, creative use of space, and by contributing to social cohesion (Richards \& Palmer, 2010). This is why some events have become inseparably linked to a city (Frost, 2012). Hall (2012) refers to these as hallmark events. Hallmark events have built a tradition in a place and have become a destination brand. Getz (2012) refers to some events as institutionalized: "they are expected to perform important social, cultural and economic roles and so they receive the support of powerful stakeholders as well as their resident communities" (p. 27). This perspective emphasizes the way events can serve the city.

On the other hand, van Aalst and van Melik (2012) described placeless or footloose festivals, which are not bound to one place, and that can move if they perceive conditions to be more favorable elsewhere. Therefore, van Aalst and van Melik (2012) suggested that whereas festivals are increasingly seen as an important means for places to stand out in interurban competition, the importance of places for festivals seems to be becoming weaker.

\section{Material or Physical Conditioning}

Material or physical conditions influencing event practices can be the weather conditions, the physical surroundings, and the location of the event practice, but also the festival staging in terms of tents, stages, event logistics, special effects, and possibilities for eating and drinking.

The central question for eventful cities regarding material and physical conditioning is how is the city staged for an event? The term staging can have multiple interpretations. Ferdinand and Williams (2012), distinguished stage set up, managing event logistics, staging event experiences, and staging large-scale events. However, when applying a practice approach, it is important to realize that the city is not just the static background or décor for the event. Instead, the physical conditions directly influence the way the practice is performed, implying a more dynamic relationship. Smith's (2016) study on events in the city made an important contribution to this notion by describing the development from the city as stage for the event, to the city as "staged" for the event, resulting in a more active and dynamic interaction between city and event.

\section{Structural Conditioning: Culture and Power}

Structural conditioning was divided by van der Poel (2004) into a cultural dimension, which emphasized the regulation of interactions, and a power dimension, which dealt with the use of resources. The cultural dimension entails the shared meaning that people attach to an event, which makes it possible to make sense of the event and communicate about it. Ryan (2012) described how an event is perceived as having meaning for the individual. He made a distinction between temporary and enduring meaning and identification. Following Giddens (1991), he described identification as a two-way process; one's own sense of being is strengthened by attending or organizing the event.

Processes of identification are dependent on a shared set of rules (van der Poel, 2004). The relationship between cities and events is subject to many explicit rules and regulations; in order to stage events, permits are needed and safety regulations have to be applied. Besides formal rules and regulations, event practices often develop their own specific unwritten rules, which only apply within the context of the event practice. These unspoken rules contribute to the shared sense making of the event. Durkheim (1893/1997) already described this 
in his work on organic solidarity and constitutive practices. Because these rules are created from within practices, bottom up, they are not perceived as a constraint by the participants. It is in these constitutive practices that an explanation can be found of how strangers can mingle and interact safely in public (Rawls, Jeffery, \& Mann, 2013).

The power dimension of van der Poel (2004) focused heavily on resources. Following Giddens (1984), power is described as originating from the control of resources. A distinction is made between material and organizational resources. Material resources for events include the event budget, the amounts of public funding the event manages to obtain, sponsoring, and donations. The relationship between events and cities is often dominated by a discussion over financial resources. However, events also need considerable organizational resources, which include political networks, public authorities, local community, volunteers, and relations with other local event organizers.

By applying a practice approach to the concept of the eventful city it becomes clear that viewing the city as a stage for events is a very limited approach. The city is not a mere backdrop, but an important actor that can condition the way in which events are created, developed, and behave through its important influence on the physical, time-space, and structural elements of the event practice. Because these conditions are constantly changing, the relationship between cities and their events is a dynamic one. This also explains why the event portfolio or program of cities tends to fluctuate over time. Instead of posing a dichotomy between city and events, the practice approach adopted here focuses on the changing roles of the event and the city as actors within the event practice. This leads us to the following research question: How is the dynamic relationship between the city and the event performed within the urban event practice?

\section{Methodology}

In order to focus on the dynamics of the eventful city practice, this article adopts a case study approach that allows us to chart the changing relationship between one city and a single event over time. This case study is part of a larger research project about events as a means for creating social cohesion and community engagement in the network society. Because event practices are produced by people and organizations acting together, they can reveal patterns of solidarity, which make them important in the study of new forms of community and social cohesion. The case study selected of this study was the Incubate festival in Tilburg, the Netherlands.

Incubate festival was purposefully selected as a case study for several reasons. Firstly, the event practice takes place in an urban environment, cooperating with cultural venues, local artists, volunteers, and businesses. Secondly, the event draws a large and diverse international audience. And thirdly, the relationship between the event and the city of Tilburg is very dynamic, which makes it very suitable for studying how an event practice emerges, develops, and dies. For more than 10 years, the event has been financially supported by the municipality. Nevertheless, after the 2015 edition of the event, when the revenues of the event were much lower than expected and additional financial support from the local government was necessary, the value of the event for the city was questioned by both policy makers and the general public. Incubate festival was criticized heavily in the local media, and the question was raised if the financial support for the event should be continued. During this study, which was conducted from 2015-2017, the municipality decided not to fund the event anymore, because the value of the event for the city was no longer evident.

The study takes a qualitative approach and is based on ethnographic methods. Ethnographic methods such as participant observation and interviews are very suitable for researching practices because they disclose the rich details of the practices (Spaargaren et al., 2016). An observation scheme was developed, based on the concept of interaction ritual chains (Collins, 2004) in combination with Spradley's (1980) dimensions of social situations. This approach emphasized the ways in which participants created shared rituals and meaning through the practice, and data were therefore gathered on how participants moved through the festival and interacted with other participants and performers. Participant observation took place during the 2015 edition of Incubate. Both the author as well as a team of 12 research assistants wrote detailed 
field notes in order to get a detailed view of the event practice.

Furthermore, 18 interviews were conducted with relevant stakeholders, such as the event organizers, visitors, volunteers, and artists. The interviewees were selected based on actor-related conditions (van der Poel, 2004), such as event-related knowledge, skills, and experience, which influences their position within the event practice. The most important selection criteria was a high level of involvement with the event, and there was a specific focus on actors who had been involved with the festival over a number of years, offering a historical perspective on the development of the practice. Some of the interviewees had also been directly involved in negotiating various kinds of support from the city, and could therefore comment on the development of the event-city relationship. Analysis of the changing role of the festival in the event policy of the city was made from the policy documents and reports produced by the Economic Development Department of the city, which is responsible for advising on event licensing and support.

During the semistructured interviews respondents were asked to describe, among other things, their actions, thoughts, emotions, and the meaning of the event practice through specific examples. During the course of the study, it became clear there were questions being raised about the future of the Incubate festival. This provided an interesting opportunity to incorporate the potential discontinuation of the event practice in the interviews.

After transcribing the interviews, a thematic analysis of the textual data was conducted using the qualitative data analysis software MAXQDA. The first layer of coding was based on characteristics of the practice and contextual conditions (van der Poel, 2004). A second and a third layer of coding was based on the emerging themes from the data.

Most of the data were gathered in the Dutch language. The quotations of participants were later translated into English. In order to avoid loss of meaning, both a Dutch and an English native speaker checked the translations.

\section{Incubate Festival: The Event Practice}

Since its first edition in 2005, Incubate festival in Tilburg, the Netherlands, has been celebrating “cutting edge culture.” The name Incubate refers to the festival's aim of being an incubator for new and innovative cultural and specifically music initiatives. Starting as an experimental punk and noise festival, over the last 10 years the festival has grown into a one of the leading independent culture festivals in Europe. The festival attracts 14,000 visitors from over 30 different countries. In 2015 the European Festival Awards (Incubate, 2015) nominated the festival for Best Indoor Festival.

The festival is described by the interviewees as surprising and a means of discovering new music. There is a general consensus in the interviews that the festival is not mainstream and it offers a wide range of music that is experimental and sometimes extreme. The respondents describe how they are surprised by musical acts that they did not know existed:

For example, an Icelandic DJ, who looked like some kind of elf, that you do not know what you are looking at. (Respondent 17)

Most visitors describe the music as the most important element of the festival. Other forms of art are seen as complementary, but not crucial. The festival has existed for over 10 years, but according to most respondents it has maintained its innovative concept, although some respondents believe that in the last year, the festival has developed too far into a particular (metal) niche.

\section{Time-Space Conditioning}

Incubate takes place every year for 1 week in September in the city center of Tilburg. The festival is embedded in the city, bringing together cultural venues, artists, volunteers, and businesses. Tilburg is a city in the Brabant province in the south of the Netherlands. With its 200,000 inhabitants, it is the sixth largest city of the Netherlands. Tilburg used to be an industrial city with an economy focused on textile factories. Like many former industrial cities, with the closing of these factories in the 1970s, Tilburg experienced a severe crisis and was looking for new development directions (van Boom \& Mommaas, 2009). Promoting culture was seen as one of the ways to create a new identity. In 1997, Tilburg became, together with Amsterdam, the first city in the Netherlands to embrace the development 
of art and culture as the engine for the economy (van Boom \& Mommaas, 2009).

In 2011, Tilburg extended this focus on creative economy to events. The ambition to become an eventful city was explicitly stated in the policy document "from city with events to event city" (Gemeente Tilburg, 2011). This document has led to more focus in the city's event policy, stating that every year three image-determining events should be organized. These events are defined much like Hallmark events (Hall, 2012) but with the specific goal of enhancing Tilburg's international image. Next to this, events should communicate the identity of the city, which was described through the following core values: decisive, experimental, innovative, creative, and an eye for talent development (Gemeente Tilburg, 2011).

Tilburg does not have the aesthetic beauty of its surrounding cities. Instead, the interviewees describe it as having a rough edge. Tilburg is a city of two faces: an innovative, creative side (the university city) and a more traditional face (the working-class city). This is also reflected in the events that Tilburg is hosting — on one hand the highly innovative and cutting-edge culture festival Incubate and on the other hand, for example, Europe's largest traditional fair (kermis).

The themes that emerge from the interviews give a clear picture of Tilburg as a setting for Incubate festival. The picture that is painted is that of an ugly city that does not have the beauty of the surrounding cities. The interviewees who live in Tilburg, or who visit Tilburg frequently, see Tilburg as a not very beautiful but "edgy" city. Interviewees who visited Tilburg for the first time during Incubate festival give a very different description of Tilburg. They describe Tilburg as pretty, cozy, and with a very nice atmosphere. The respondents can see themselves visiting the city again "perhaps for a romantic weekend” (Respondent 16). This indicates that the perception of the city is changed by the event practice.

In the minds of the interviewees, Incubate festival and the city of Tilburg are closely linked together. The first thing that stands out is that many of the interviewees who do not live in Tilburg only know the city because of Incubate and they only visit the city during the festival. This holds for both Dutch and international visitors:
I have never been there . . . outside Incubate. (Respondent 4)

I didn’t even know about Tilburg actually ... that it existed. Yeah [laughs]. (Respondent 5)

Many respondents value the size of Tilburg, describing it as not too big and not too small, and as having a "village atmosphere." According to the interviewees, this also makes Incubate work so well in Tilburg. It is large enough to accommodate the many different venues and places. However, it is small enough to be able to explore these spaces on foot or by bicycle, and for the festival to really stand out and be noticed.

The interviewees value the vibrant cultural and musical climate of Tilburg. People refer to the many music venues, the music education institutes, and to other festivals that are organized in the city. Specifically, people refer to Tilburg as a "metal city" and to Tilburg as a city of young creators:

\begin{abstract}
Music scenes are alive here, especially the things that I am interested in. A lot of Metal. Many musicians, many. (Respondent 6)
\end{abstract}

I don't know how come, but in general ... more is done music wise.... Yes, perhaps people grew up with it. (Respondent 8)

The cultural and musical climate of Tilburg becomes visible through the festival and stimulates the interaction between musicians contributing to the cultural scene. Incubate is an opportunity to meet each other and to connect and talk about each other's projects:

\footnotetext{
There are just many people busy with making music, but it stays under the surface a bit. And via Incubate, I know from a lot of people what they are doing, because I meet people ... I think people here in Tilburg also find each other through Incubate. (Respondent 7)
}

The majority of the respondents believe that Incubate is inseparably linked to Tilburg, although some also believe it could be organized in a different city. However, most neighboring cities are not seen as suitable, because they lack the cultural climate, the music history, and the many venues that would support the festival or they are just considered too mainstream. 
The Rhythm of the Festival. An important change in the space-time conditioning of the festival occurred during the course of this study. For 10 years, Incubate festival had been organized for 1 week in September. In 2016, 3-4-day versions of the festival were organized three times, in May, September, and December. For the majority of the respondents, the festival is supposed to be organized for 1 week in September. It has become "natural" for the festival to be organized then. The interviewees value this week, because it allows them to immerse themselves in the festival and because it is fixed in their diaries and those of their friends:

Incubate was really a feeling, because you immersed yourself in culture for a whole week . . . I went every day.... That was that feeling. Really immergence. (Respondent 6)

Moreover, a whole week of festival stimulates the feeling of togetherness. One of the respondents describes how meeting the same people every day at different venues creates a feeling of togetherness and surprising conversations:

Because you meet the same people all week. Maybe around 200-500 people you see every day, and during the weekend new people are added to that group. It really forms a bond. (Respondent 15)

The change to three editions of the festival per year is discussed by the respondents as well and the opinions differ. Some visitors, who live in Tilburg or close to Tilburg, appreciate the change because they see it as more of something they like, and because 3 days are easier to plan away from work than a whole week. But not everyone likes it. The staging of the festival three times through the year seems to change the feeling of it being a "special" time. According to some respondents, the change in rhythm leads to a more local focus instead of an international. In addition, the range of locations, which is seen as one of the strong points of the festival, was perceived to be less in the 2016 editions, making the event less integrated into the fabric of the city. Some of the respondents only went to the September edition, some saying it was hard to mobilize their friends to go.
Virtual Space. For the event practice of Incubate, the virtual space plays an important role for the visitors in preparing for the festival and designing their own route through the festival. Because of the many different locations and types of music, many choices have to be made. The Incubate website provides information about all the different performances, which makes it possible for the visitors to design their personal festival program. Before the event, most respondents visit the website, listen to the different artists, and decide on which ones to visit:

The nice thing about this festival is that you can easily make a program based on genre. So I can just see what type of music I like and that is where I go. (Respondent 10)

I try to make a plan beforehand. A general plan, in which I plan certain escapes, just in case something disappoints me, so I have an alternative for that half hour. (Respondent 11)

During the event, the respondents describe how they keep contact with each other via WhatsApp. They inform each other about their location and if they are watching something nice. This also became evident during the participant observation. After a show is finished, people take out their phones to look at the schedule, and send messages to each other:

But often we also have a WhatsApp group, so you can see where everyone is. If you like company, then you can say like, I am here and it is really cool. ... I also like to hear that from others. (Respondent 8)

Then afterwards I App and I join someone else again. (Respondent 14)

In addition to the website, Incubate uses another online tool to engage the visitors. Uservoice is an online platform that allows people to provide tips for the festival program. Thousands of tips are provided by the festival community. The festival organizers claim that this is necessary, because they often deal with such niche music that they cannot possibly have all the knowledge to come up with an innovative and cutting-edge program by themselves. In this way, members of the audience become cocreators of the event. 


\section{Material/Physical Conditioning}

Incubate festival takes place within the city of Tilburg, in many different venues. Besides existing music venues, theaters, and local bars, performances also take place in venues that are more unusual. Performances have taken place in a church, a nature theater in the forest outside Tilburg, and in an old school bus, which was parked on the market square. From the interviews, it shows that these physical surroundings form a very important part of the event. Both the surprise aspect of these venues and the fact that new venues can be discovered every year are part of the attraction of the event:

Hearing music in somewhat strange locations . . . the combination of locations and music is always attractive. (Respondent 10)

What I notice is that the locations change a bit every year. ... There was a little park with an outdoor stage, but that has disappeared. Then other new locations are added. I always enjoy that. (Respondent 18)

In the interviews, many venues are mentioned, but some specific venues seem to have a lasting impression on the visitors, such as the Paulus church. This is a historical church building the city center of Tilburg, which was built in the year 1822. The church, a national monument, is still in use for religious services, as well as for other activities:

The Paulus Church ... . the first time I went there it was magical. It is a place, which I pass on my bicycle every day. But I had never been inside. Yes, magical. ... Goose bumps. (Respondent 11)

Because of the many different venues throughout the city, logistics are something that comes back in the interviews as well. People walk from one venue to the other, in small groups. Most people find this a very pleasant way of exploring the city:

It is a city full of hidden places. And they all become visible when you have to go there, because there are bands in a basement, or in a factory hall somewhere. This way you also get to know the city a bit, and people from outside get to know the city in an unusual way. (Respondent 11)

This means that you sometimes walk at least 10 to $15 \mathrm{~km}$ a day. (Respondent 15 )
The festival requires some logistical preparation. Because of the tight schedules, and the many options, visitors have to plan ahead; otherwise they will arrive everywhere too late. This happened to the author during the first day of participant observation, and one of the interviewees confirms it:

But I found out that Incubate is really something for people who have been going there for years. They know that you really need to plan. You cannot just go everywhere, because the locations are far apart. It was more of a treasure hunt through the city than a real festival for me, but the veterans said, yes, you just have to know where to go and plan ahead. (Respondent 3)

Because of the fact that unusual venues are used, and many of the performances take place indoors, the feeling of a "secret society" is created. The festival takes place during the day and in the evenings, when the residents of Tilburg are simultaneously acting out their daily routines in the city. The fact that there is a festival going on is visible to outsiders, because of the presence of many different subcultures with their clothing styles, but it does not affect the daily life of the residents. The attendees wear wristbands, which give them access to all the, sometimes hidden, venues. They recognize each other by the wristbands, but also by their different clothing styles. Nevertheless, because there are many different performances at the same time, there are many shallow, almost invisible streams of festivalgoers crisscrossing the city. This underground current of experimental and exciting art and music is flowing at the same time the local residents go to work, walk their dogs, or sit on cafe terraces.

\section{Structural Conditioning}

The Symbolic Dimension. Because members of many different subcultures perform the Incubate event practice, one would assume, at first sight, that there are also different meanings attached to the festival. However, the interviews show a coherence in meaning is created within the event practice. The fact that Incubate is a festival of many subcultures becomes clear in the interviews. Some of the subcultures that are mentioned in the interviews are metal, doom, drone, ambient, electro, indy rock, psychedelic, hip hop, punk, hardcore, noise, 
jazz, and more. Because of these subcultures, there are many people with different clothing styles in Tilburg, during Incubate festival, although the interviewees also say this is getting less distinctive. The clothing style is not necessarily what distinguishes the incubate visitors from outsiders:

I look quite normal, so to say. And there are a lot of people like that, but also many people who look much more extreme. (Respondent 7)

At Incubate you would expect a kind of alternative audience, but I think that that division in clothes and hair style is kind of disappearing. (Respondent 14)

Although many music genres and subcultures are represented at Incubate festival, what really binds people together during the festival is their deep love of music. This is also reflected in the respondents' description of the "Incubate feeling." People describe how they are touched by the music during the event, either intellectually or emotional. Intellectually, because there are many musicians among the audience, and they also like to watch musicians play skillfully:

Something I never saw or heard performed like this before. Or he or she is performing it so well ... a craftsperson, who knows what he is doing. (Respondent 18)

Emotionally, there are many descriptions of becoming immersed in the music. Respondents describe the music as "dreamy," and they are "dreaming away" with minimal or ambient music. The respondents describe the whole festival as an immersion in a different reality that leads them to forget daily life and worries, and which has an impact on their state of mind:

I always leave, it sounds very strange, with different brain waves than when I went there, so to say. (Respondent 9)

When asked how all these different subcultures can fit into one festival, the respondents refer to the open mindedness of the visitors, towards different music genres, but also towards other visitors. The whole festival is about discovering new things.

It is clear from the interviews that Incubate leads to a sense of belonging for the visitors. Moreover, by bringing together a large number of (sometimes extreme) subcultures, the festival is a place for performances and for people outside the mainstream culture. In that sense, Incubate manages to include people who do not feel included otherwise.

From the interviews and the participant observation several cultural elements regarding the event practice emerged. Firstly, the connection between audience and performers is very close. Performers are very approachable, and often performers become the audience for the next performance. Several times during performances, audience members make suggestions to the performers, or have a small conversation with them. Due to the enormous number of performances, the changing of the equipment needs to be done fast, and if something is not working, there is a cooperation between performers, audience, and volunteers to get everything solved. Furthermore, the more established artists announce on stage that after the concert they would like to join the audience during the rest of the festival:

I always liked it that many artists came to the after party, and you could have conversations with them. (Respondent 18)

Secondly, two variations of the festival experience became visible. Because of the diverse and large number of performances, visitors develop their own itinerary through the festival. This results in a very fast pace of the event. Two minutes after the end of a performance, the venue is completely empty and the audience is rushing to get to another act. During informal talks at the event, several visitors recommended a bicycle to get to the different venues as fast as possible. Others commented that the festival was quite exhausting, and they needed to recover from the overload of experiences during the week:

You have to move around a lot during this festival. At some large festivals, you can perhaps go with a group from stage A to stage $B$, but here you have 30 stages. So, then you have to take a bike, or walk. And you have to have a certain pace if you want to see things and not arrive everywhere too late. (Respondent 11)

On the other hand, there were also people who had a very quiet festival experience by limiting 
themselves to one type of music, which took place in one venue. These included the metal performances in the nature theater, or the minimal music in a hotel basement.

Thirdly, the festival is still rooted in underground culture, although it would like to distance itself from that term. There are references to the do-ityourself (DIY) attitude of punk rock, and an open, sharing, noncommercial mentality. Some interviewees distance themselves from the mainstream music and festival industry, which they consider to be too commercial and unauthentic.

Shared Rules. The shared meaning of an event practice depends on a shared set of rules. Both from the participant observation and from the interviews several context-specific unwritten rules were revealed. The one rule that was mentioned by almost all interviewees was no talking. In general, people come to listen to the music, so chatting to each other is not appreciated. It seems the no talking rule is dependent on the location and the music genre; for some of the quieter, singer-songwriter, or ambient genres this is mentioned by all respondents, and in locations where people sit down, this is mentioned specifically. But some respondents also apply this unspoken rule to the louder metal or noise music:

That also means that when a DJ is playing, or something loud is going on, and you are just busy with your in-crowd, without paying attention, that is generally not appreciated. (Respondent 18)

A second category of unwritten rules that emerged from within the event practice deals with door regulations. This became evident during the participant observation. Because of the adventurous character of the festival, and the unknown acts that are performing, the audience is allowed to walk in and out of the performances during the acts. But these door rules are not straightforward. They can differ per performance, and sometimes they are adapted during the course of the festival. For example, in bars and music venues people walk in and out of performances as they please, but in the theaters people wait until in-between songs, and after some songs, there is a shift in audience. During theater plays, the doors close and it is not allowed to leave or enter in the middle of the play.
During the second day of the festival, as part of the participant observation, the author decided to ask a volunteer about the informal door regulations, which so far seemed to work, but were not spoken about. This was while waiting in line before entering a music performance in a theater. When asking the volunteer explicitly if it was allowed to leave during the performance, it turned out that the volunteer was not sure what the procedure was, and he became hesitant to answer the question. In response to the question, the volunteer decided to consult the performing band, who were backstage preparing for their act. Upon return, the volunteer replied that the band did not mind people leaving early if they wanted to attend other performances. This example illustrates the tacit cultural knowledge of the festival community. These rules, emerging from the practice are not routine, they are flexible and although people behave according to them, they find it difficult to make them explicit. These are the unspoken rules that make the practice work.

\section{Power Dimension}

Material Resources. Until 2016, Incubate festival was financially well-supported by the city of Tilburg as well as the province of Brabant and several public and private funds, resulting in a budget of 500,000 euros in 2013 and 2014 (Incubate, 2015). The municipality of Tilburg developed a system to distribute event subsidies based on the policy document "from city with events to event city" (Gemeente Tilburg, 2011). Events that matched criteria such as attracting more visitors to the city or enhancing the city's image were given priority in the allocation of subsidies. Incubate, although not in the top 10 of Tilburg's most visited events, was marked as one of the four "image determining events” (Gemeente Tilburg, 2016). The distinctive character of the festival was seen as enhancing the image of Tilburg as a place to produce and consume cutting-edge culture, and bringing creative consumers and producers to the city. This meant that Incubate received a relatively large amount of financial support, but this also made the festival very dependent on subsidies. Moreover, it led to the festival adopting more ambitious and expensive programming. As a result of this, Incubate encountered financial problems in 2015. 
The financial problems generated severe criticism of the festival, both from within the local government as well as from the local press and the general public. When the amount of financial support was revealed in the press, it caused a division of opinion about the value of the festival. On one hand, many people were supportive of the festival, but on the other hand, there were also voices that objected to the large subsidies that Incubate received, particularly as a niche festival. The festival organization explained the financial problems in terms of a portion of the subsidy they had not received and by the fact that they did not have enough paying visitors. From the interviews, it also emerged that many of the respondents who visited the festival did not buy a ticket, because they were involved with the festival as volunteers, artists, or providers of home stays. This means that the largescale involvement of local residents and other visitors undermined festival finances:

At the entrance, we never had to pay, because we were on the guest list. You could choose what you wanted to donate, so we bought a T-shirt every year. (Respondent 18)

Well, it hurt a bit when they said they do not have enough paying visitors, because I am someone who does voluntary work for them, so I get to go for free. I never have to pay. And now they have to change that somehow. (Respondent 1)

After several months of uncertainty and a change in festival management, the local government demanded a new business model from Incubate. In order to attract more paying visitors and at the same time still meet the criteria for various subsidies, the organization decided to change the rhythm of the festival. When the festival organization managed to present this new model, including the new timing, support for the festival was continued for another year. However, despite positive results in 2016, finances became a problem again in 2017 when a major art subsidy bid was declined (Fonds Podiumkunsten, 2017). Because of this, the province of Brabant decided not to fund Incubate anymore, and in February 2017, the news arrived that the municipality had also withdrawn financial support for Incubate festival, mainly because they did not want to be the sole public body supporting the festival. The municipality stated that the new plan, which was presented by Incubate, deviated too much from the original format. Therefore, the event now scored significantly lower on the subsidy criteria (Gemeente Tilburg, 2017), such as contribution to the image of Tilburg, target audience, timing and location of the event, and the ratio of local subsidies versus other sources of income (Gemeente Tilburg, 2017).

Organizational Resources. Incubate's organizational resources include the participating venues, political networks, and the local inhabitants of Tilburg and its international and local community. Incubate has always had a good relationship with the participating venues. In every edition, different and unusual venues take part. Incubate festival offers the opportunity to book more artists that are unusual and attract a different audience.

Because most performances take place in indoor venues, most of Tilburg's residents are not involved in these acts. In order to involve the local residents, Incubate offers a “zero” program: performances that are free of charge, sometimes taking place in the public space. An example is the art project "play me I'm yours" by Luke Jerram in 2011, an installation of 103 pianos for people to play in different locations around the city. This project had been carried out before in cities like New York, Barcelona, London, and Adelaide, but never with such a large number of pianos as in Tilburg (Brabants Dagblad, 2011). Local residents were also surprised and charmed by the project "Lullaby" by the same artist in 2014, involving a parade of musical and illuminated bicycles through the city. In 2015, Incubate organized a local beer market in the city center as one of their activities, where the locally brewed Incubate beer was sold to the public, together with other small local brands. This is another example of how the festival connects to local residents who are not necessarily interested in the experimental music of the event. Incubate takes place in the city center, when the local residents proceed with their ordinary activities. According to many visitors, the reactions of local people are positive.

On the other hand, there is a large group of residents in Tilburg who do not know the festival or do not support it. It is not a mainstream festival, which makes it difficult to explain to people who do not 
like this type of music. This reflects the two groups present in the city: one group supporting progressive culture, the other group preferring events that are more traditional and well-known events that are not necessarily linked to the city:

\begin{abstract}
And I think it is very difficult for other people, when people see posters of a festival with bands that you never heard of and you see all these strange people walking. That does not feel very accessible for a lot of people, I guess. (Respondent 6)
\end{abstract}

One of the organizers describes the relationship between Incubate and political networks as a complex love relationship. Over the years, Incubate has received financial support from the local government, and it also became an important feature of its event portfolio. But it also encountered some difficulties in explaining the value of the festival for the city. With regard to the local political networks, the question "does the event serve the city, or does the city serve the event?” has become very relevant, to the point where the local government decided to stop supporting the festival. In the last few years, the organization of Incubate had the feeling that it became a "football" in a political game being played between political parties. But some interviewees, artists, and visitors were also quite understanding about government decisions:

\begin{abstract}
When you have a loss, year after year, then I understand that at a certain point the municipality says: wait, something has to happen, otherwise it just does not work. (Respondent 15)
\end{abstract}

\section{The End of Incubate?}

In a practice approach, it is not only important how a practice is created and maintained, but also how a practice is eventually abandoned or killed off (Hargreaves, 2011; Shove et al., 2012). In the interviews, a question was added about what would happen if Incubate no longer existed. When the interviews were conducted, this was already a likely scenario. Several different reactions emerged from the interviews. The most common reaction was missing the festival practice. The respondents describe how they always looked forward to the festival and how they discover new things at the event. The people who live in Tilburg describe a feeling of pride in their hometown during the event:

That feeling of being on my bicycle or on foot, here somewhere in the neighbourhood. And cycling from stage $\mathrm{X}$ to stage $\mathrm{Y}$. And thinking, wow, you can walk for days in your own city, between places, but you share it with your neighbours. At that moment I am very aware of the festival and what is so nice about it. That overall feeling, in a weekend or a week. I would really miss that. (Respondent 11)

Others refer to the network and sense of togetherness that would disappear. They are afraid that the reason for creatives to get together will be gone. Moreover, people refer to what Tilburg as a city would miss, such as a decline in cultural climate, but also in the attractiveness of the city:

It would be a shame for Tilburg, because we are not number one in looks, appearance and those things. So I think, this was something that made people from Amsterdam come to Tilburg. And they will not come for the fair (Kermis) or a traditional music festival ( festival van het levenslied). Because they have those things themselves. (Respondent 11)

On the other hand, there are also people who believe that the disappearance of the festival is part of life, and not the end of the world:

It is really a shame that it will disappear. But I don't think I will get withdrawal symptoms in September. Well, things come and go. (Respondent 2)

I would really miss it, but well, that is part of life, sometimes. (Respondent 16)

It is very interesting that people describe what they would lose if the practice would disappear, and it becomes very clear that in their minds the event is interlinked with the city. In their descriptions, the respondents indicate that they would miss an urban practice, not just an event. On the day the decision was made that Incubate festival would not be prolonged, Tilburg's city poet wrote a poem about the event called "Requiem," in which he also made a direct link to the city, changing the name Tilburg into "Stilburg," referring to the emptiness and silence (stil is Dutch for silent) that would be a result of the disappearance of Incubate festival: 
“...

de makers zien de leegte

komen en benoemen deze

stad heet vanaf nu Stilburg”

(Martin Beversluis, 2017)

“...

the creators see the void

come and call this city

from now on Stilburg”

(Martin Beversluis, 2017)

\section{Discussion and Conclusions}

After analyzing the event practice of Incubate festival in its context of the city of Tilburg, several conclusions can be drawn. The main research question of this study was to analyze how the relationship between the city and the event is performed within the urban event practice. We can conclude that the relationship between the city and the event is very dynamic and interactions takes place on different levels. At one level, the city forms the multidimensional context, which enables or constrains the event practice. At the same time, the city and the event are actors producing the practice, who might have contradicting goals. Finally, within the urban event practice, the event and the city are entangled and the practice only makes sense because of the event and the city interacting together.

One of the goals of this study was to examine how the contextual dimensions (van der Poel, 2004) relate to the way the practice is performed and perceived. By zooming in on the context of the event practice, it becomes clear how multidimensional the context is. The case study shows that the contextual conditions not only influence the practice, but they also influence each other. Furthermore, the different contextual conditions do not necessarily lead to synergy, but instead they can also contradict each other. In the case of Incubate festival, some of these contractions have led to problems in the relationship between the municipality of Tilburg and the festival. For example, the interviews show that participants are proud to be involved in the festival by acting as a volunteer or by providing other kinds of services to the festival. This is rewarded by free access to the event, which creates a feeling of belonging among the participants, but it has also led to a reduced number of tickets sold and increased financial difficulties for the festival. As a response to the financial problems, the organizers changed the rhythm of the event in an attempt to keep the practice going. This change in rhythm led to a different event experience and according to some respondents a reduced sense of togetherness, which illustrates how difficult it is to change rhythms and routines that have come to be "natural" over the years.

Secondly, this study shows that the event practice is tightly connected to the city of Tilburg. One of the respondents states that the event felt more like "a treasure hunt through the city than a real festival." This is an important example of how both the event and the city are performed within the practice. The event leads people through the fabric of the city, but with a logic that belongs to the festival, rather than the places in the city. In their study about city festivals and urban development, van Aalst and van Melik (2012) asked themselves “does place matter?" In this case, place clearly matters for the festival and vice versa. The city is perceived through the lens of the event, and the event is perceived through the lens of the city. Moreover, the perception of the city is changed by the event practice.

Because of this, the city and the event cannot be neatly organized into two separate entities, in which the city provides benefits for the event and the event provides benefits for the city. Instead, they are entangled into one "eventful city practice." Smith (2016) described how the city can be staged for the event; urban space is produced through performances (Merx, 2011) within practices. This case study is an example of how urban space is produced by staging an event; the city shapes the event and the event shapes the city.

This holistic perspective of city and events has implications for the way we perceive value creation through events. Value creation cannot only be depicted as a flow from the event to the city. Instead, it should also be seen in a more holistic way: the city and the event together produce value through the urban event practice. In the case of Incubate festival, the large number of volunteers Incubate is drawing can be seen as practitioners that are recruited by the practice (Shove et al., 2012). But it is not just the event that is supported by this; it is 
also the city that people are implicitly supporting. People who identify with the practice (Ryan, 2012) implicitly identify with the city. If we continue to view the event as separate from the city, then this value is not recognized, and the low number of tickets sold becomes the focus of the discussion.

A more holistic perspective also has implications for the development of event portfolios within cities. Cities aim for a balanced event portfolio in which events are strategically planned in order to generate a range of social and economic benefits (Antchak, 2016; Ziakas, 2014; Ziakas \& Costa, 2011). This is generally seen as a way to change a "city with events" into an "eventful city” (Richards \& Palmer, 2010). From an "event portfolio perspective,” Tilburg can easily replace Incubate festival with another cultural festival, balancing the supply of different event types in the city, and catering for the different target groups within the city. However, this study shows that the city and the event cannot be seen as separate from each other. By removing the festival, the city context itself also changes. Because of the entanglement of city and event within the event practice, discarding the festival also means discarding a part of the city's identity.

Finally, the question arises, why was the event practice eventually killed off? A partial explanation can be found in the social value that was overlooked, by regarding the event as separate from the city. The focus of the discussion is not the commitment of the community to the event practice, but the financial problems. But when we look at how eventfulness is created within the practice, another issue emerges regarding the visibility of the event. Visibility and image creation are important issues, because they are primary goals of Tilburg's event policy (Gemeente Tilburg, 2011, 2017). Incubate festival effectively becomes part of the cultural "underground" (Cohendet, Grandadam, \& Simon, 2010) of the city for a few days. Although this creates a "special" feeling for the participants, it does not contribute to the visibility of the festival for outsiders. The data show that Incubate is distinctive for participants, but it is hidden within the fabric of the city, and therefore does little to create a distinctive image for the city, and does not meet an important aim of Tilburg's eventful city policy.

Moreover, there is learning involved in the festival practice: you have to find your way through the supply of music, design you own program, and arrive everywhere on time. Together with the unusual music styles, this creates a barrier between insiders and outsiders (Collins, 2004), which generates high levels of eventfulness for a particular group, but lower levels of eventfulness for the city as a whole. Therefore, a successful and innovative event will not always add to the eventfulness of the city. Despite efforts to engage with the city and to make the event accessible and visible, Incubate eventually could not convince Tilburg that it should be part of its "eventful city practices," even though it matches the core values of the city. In effect, Incubate did not contribute to making Tilburg an eventful city because the aims of the event (creating a distinctive space for festival goers) did not match the aims of the city (creating a distinctive image for Tilburg). This explains to a large extent why the relationship was discontinued.

Overall, by applying a practice approach to an urban event, it has become clear that an "eventful city" is more than a city utilizing events for strategic aims. The dichotomy of city versus event results in conflicts about "who is serving who" and in a limited perspective on the way value is created through event practices. Instead, the application of the practice model and a focus on the actual "sayings and doings" of the event practice leads to a more comprehensive approach. The festival seems to create its own space, with its own rules and with an atmosphere in which new things can be created. This "third space" (Soja, 1996) is neither inside nor outside the city, but it is a different type of space in which new things can happen including a renegotiation of rules and cultural identity. In this sense, the event creates space for the city, and the city creates space for the event.

\section{Acknowledgments}

I am grateful to Dr. ir. Bertine Bargeman for sharing her specialist knowledge of the practice approach. Also, many thanks to my colleagues from NHTV Breda, Dr. Esther Peperkamp and Nienke van Boom MA for their useful and motivating comments. Joost Heijthuijsen, Miriam van Ommeren, and Vincent Koreman of Incubate festival, thank you for giving me the opportunity to conduct this case study. Also, thanks to the students of the BSc. Leisure Studies 
at NHTV Breda, who assisted enthusiastically in the participant observation. Finally, thanks are due to the three anonymous reviewers for their helpful and detailed comments and to Alba Colombo for her assistance in editing this article. This research was supported by the NWO Doctoral Grant for teachers.

\section{References}

Antchak, V. (2016). Event portfolio design: Exploring strategic approaches to major events in New Zealand. Ph.D. thesis, Auckland University of Technology, Auckland, New Zealand.

Bargeman, B. (2001). Kieskeurig Nederland: Routines in de vakantiekeuze van Nederlandse toeristen. Ph.D. thesis, Amsterdam, the Netherlands.

Beversluis, M. (2017). Requiem. Retrieved from http://beversluis.com/?s=Requiem

Brabants Dagblad. (2011). Incubate halt meer dan 100 pianos naar stad en omgeving. Retrieved from http://www. bd.nl/regio/tilburg-e-o/tilburg/incubate-haalt-meer-dan100-piano-s-naar-stad-en-omgeving-1.3381564

Cohendet, P., Grandadam, D., \& Simon, L. (2010). The anatomy of the creative city. Industry and Innovation, 17(1), 91-111.

Collins, R. (2004). Interaction ritual chains. Princeton, NJ: Princeton University Press.

de Brito, M. P., \& Richards, G. (2017). Guest editorial. International Journal of Event and Festival Management, $8(1), 2-7$.

de Geus, S., Richards, G., \& Toepoel, V. (2016). Conceptualisation and operationalisation of event and festival experiences: Creation of an event experience scale. Scandinavian Journal of Hospitality and Tourism, 16(3), 274-296.

Durkheim, E. (1997). Division of labor in society (W. D. Halls, Trans.). New York, NY: Free Press. (Original work published 1893)

Ferdinand, N., \& Williams, N. (2012). Event staging. In S. J. Page \& J. Connell (Eds.), The Routledge handbook of events (pp. 234-247). Oxon, UK: Routledge.

Fonds Podiumkunsten. (2017). Meerjarige activiteitensubsidies Fonds Podiumkunsten 2017-2020. Retrieved from http://meerjarigeadviezen.fondspodiumkunsten.nl/advi ezen/incubate/

Frost, W. (2012). Events and tourism. In S. J. Page \& J. Connell (Eds.), The Routledge handbook of events (pp. 7586). Oxon, UK: Routledge.

Gemeente Tilburg. (2011). Tilburg van stad met evenementen naar evenementenstad. Retrieved from http://tilburg.com/ nieuws/tilburg-van-stad-met-evenementen-naar-even ementenstad/

Gemeente Tilburg. (2016). Evenementenstad Tilburg. Retrieved from http://www.nationaalcongresevenemen ten.nl/evenementenstad-tilburg/

Gemeente Tilburg. (2017). Toekennen subsidies voor evenementen. Retrieved from https://www.tilburg.nl/actueel/ nieuws/item/toekennen-evenementensubsidies/
Getz, D. (1989). Special events: Defining the product. Tourism Management, 10(2), 125-137.

Getz, D. (2012). Event studies. In S. J. Page \& J. Connell (Eds.), The Routledge handbook of events (pp. 27-46). Oxon, UK: Routledge.

Giddens, A. (1984). The constitution of society: Outline of the theory of structuration. Cambridge, UK: Polity Press.

Giddens, A. (1991). Modernity and self-identity: Self and society in the late modern age. Stanford, CA: Stanford University Press.

Hall, C. M. (2012). The political analysis and political economy of events. In S. J. Page \& J. Connell (Eds.), The Routledge handbook of events (pp. 186-201). Oxon, UK: Routledge.

Hargreaves, T. (2011). Practice-ing behaviour change: Applying social practice theory to pro-environmental behaviour change. Journal of Consumer Culture, 11(1), 79-99.

Incubate. (2015). Incubate nominated best indoor festival. Retrieved from http://incubate.org/2015/237/best-indoorfestival

Jago, L., \& Shaw, R. N. (1998). Special events: A conceptual and definitional framework. Festival Management \& Event Tourism, 5, 21-32.

Merx, S. (2011). Public pie. Performing public space. Performance Research, 16(2), 132-137.

Morgan, M. (2008). What makes a good festival? Understanding the event experience. Event Management, 12(2), 81-93.

Rawls, A. W., Jeffery, A., \& Mann, D. (2013). Locating the modern sacred: Moral/social facts and constitutive practices. Journal of Classical Sociology, 16(1), 53-68.

Reckwitz, A. (2002). Toward a theory of social practices: A development in culturalist theorizing. European Journal of Social Theory, 5, 243-263.

Richards, G., \& Palmer, R. (2010). Eventful cities: Cultural management and urban regeneration. London, UK: Routledge.

Ryan, C. (2012). The experience of events. In S. J. Page \& J. Connell (Eds.), The Routledge handbook of events (pp. 248-259). Oxon, UK: Routledge.

Shove, E., Pantzar, M., \& Watson, M. (2012). The dynamics of social practice: Everyday life and how it changes. Los Angeles, CA: SAGE.

Smith, A. (2016). Events in the city: Using public spaces as event venues. Oxon, UK: Routledge.

Soja, E. W. (1996). Thirdspace. Cambridge, MA: Blackwell.

Spaargaren, G., Lamers, M., \& Weenink, D. (2016). Introduction: Using practice theory to research social life. In G. Spaargaren, D. Weenink, \& M. Lamers (Eds.), Practice theory and research: Exploring the dynamics of social life (pp. 3-27), Oxon, UK/New York, NY: Routledge.

Spradley, J. P. (1980). Participant observation. Orlando, FL: Harcourt Brace Jovanovich College Publishers.

van Aalst, I., \& van Melik, R. (2012). City festivals and urban development: Does place matter? European Urban \& Regional Studies, 19(2), 195-206. 
van Boom, N., \& Mommaas, H. (2009). Urban regimes and evolutionary paths. In N. van Boom, \& H. Mommaas (Eds.), Comeback cities: Transformation strategies for former industrial cities (pp. 74-97). Rotterdam, Netherlands: NAi Publishers.

van der Poel, H. (2004). Tijd voor vrijheid. Amsterdam, Netherlands: Boom.

Warde, A. (2014). After taste: Culture, consumption and theories of practice. Journal of Consumer Culture, 14 (3), 279-303.
Ziakas, V. (2014). Planning and leveraging event portfolios: Towards a holistic theory. Journal of Hospitality Marketing \& Management, 23, 327-356.

Ziakas, V., \& Costa, C. A. (2011). Event portfolio and multi-purpose development: Establishing the conceptual grounds. Sport Management Review, 14, 409-423. 